\title{
The effect of core stability exercises on functional status in patients with low back pain
}

\section{Authors: Goda Obuchovičiūtè1, Ieva Eglè Jamontaitè1,2 \\ Scientific research supervisor: Alma Cirtautas ${ }^{1,2}$}

${ }^{1}$ Vilnius University Hospital Santaros Clinics, Rehabilitation, Physical and Sports Medicine Centre, Lithuania

2Vilnius University, Faculty of Medicine, The department of Rehabilitation, Physical and Sports Medicine, Lithuania

Introduction. There are insufficient research studies, analysing the advantage of physiotherapy using Dr. Wolff trainers against the core stability exercises, applied in the cases of lower back pain. Therefore, it results in the issue to reveal, if exercises with $\mathrm{Dr}$. Wolff trainers are more effective means than the core stability exercises.

Purpose. To compare the effects of two different core stability exercises programs on the functional status and quality of life of working-age persons in the cases of lower back pain.

Methods. The research was conducted at Physical and Sports Medicine Centre, Outpatient Rehabilitation Unit, Vilnius University Hospital Santaros Clinics, between November, 2016 and April, 2017. The scope of the research was 53 patients suffering from lower back pain. The average age of research subjects was $34 \pm 9.6$ years. The research included 19 male and 34 female patients. The subjects were randomized into the following two groups: a test group $(n=25)$ and a control group $(n=28)$.

The isometric trunk muscle strength of the subjects has been measured using a diagnostic equipment Back-Check created by Dr. Wolff, trunk mobility - using an inclinometer and Schober's test, pain - using a Numeric Pain Rating Scale (NPRS). The functional status has been assessed using Oswestry and Roland - Morris questionnaires, and the quality of life - using the EQ - 5D and TAMPA scale for Kinesiophobia. Data analysis has been conducted using SPSS 23.0 for Windows and Microsoft Excel 2016 software.

Results. A statistically significant increase $(p<0.05)$ in all parameters analysed in the groups was determined.

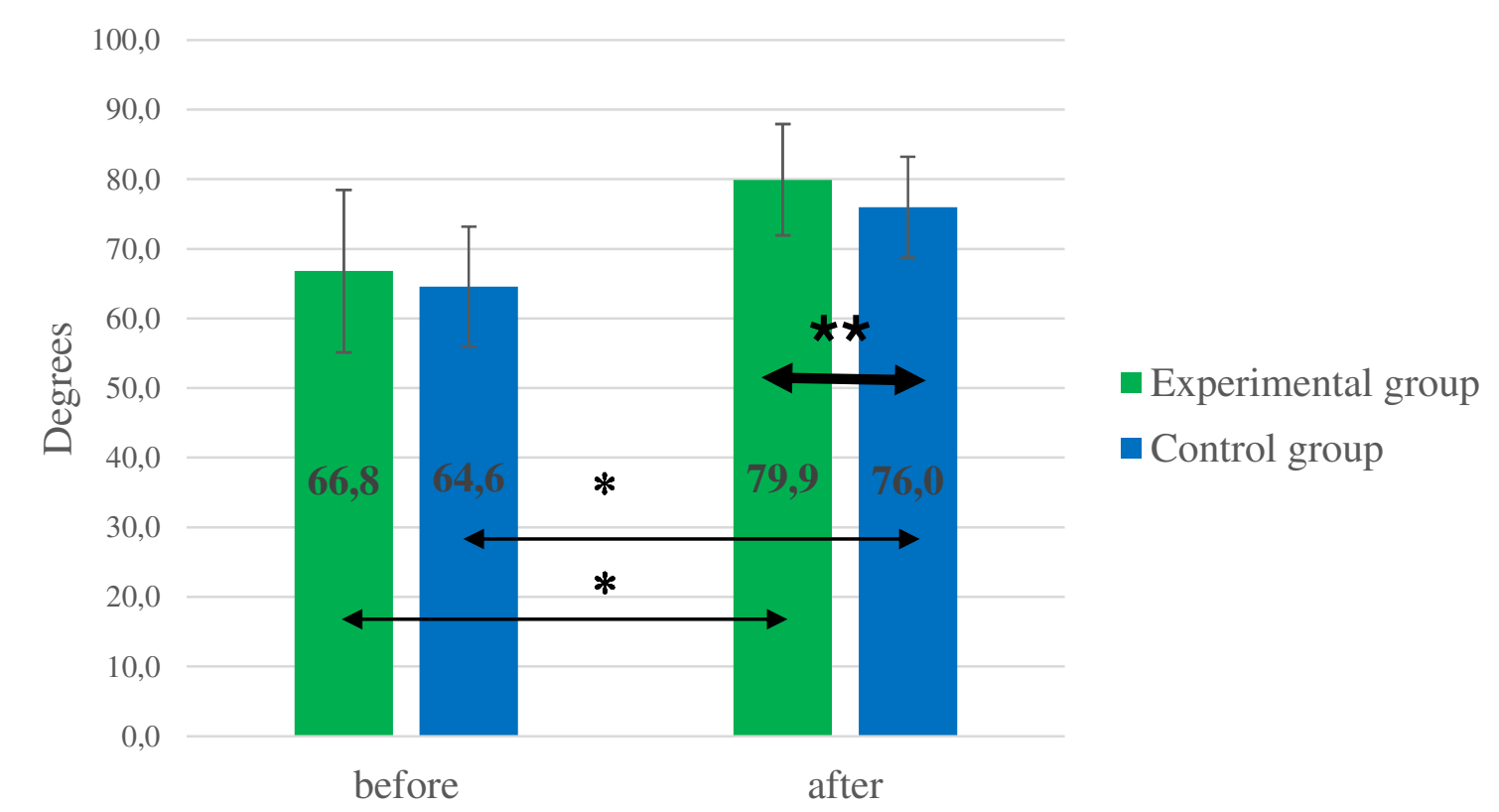

Figure 1. Trunk mobility by leaning forward and returning to a straight position results before and after different rehabilitation programs $\left({ }^{*} p<0,05 ;{ }^{* *} p<0,05\right)$.
The assessment of the research results between the groups showed a statistically significant higher increase in trunk mobility by leaning forwards and returning to a straight position in the test group, which was applied physiotherapy using Dr. Wolff trainers ( $p=0.03$ and $p=0.019$, respectively) (Figure 1). Moreover, Schober's test results showed a statistically significant higher increase in the test group in comparison with the check group $(p=0.049)$ (Figure 2). The analysis of kinesiophobia dynamics between the groups showed a statistically significant decrease in the fear of movement in the test group $(p=0.04)$ (Figure 3$)$.

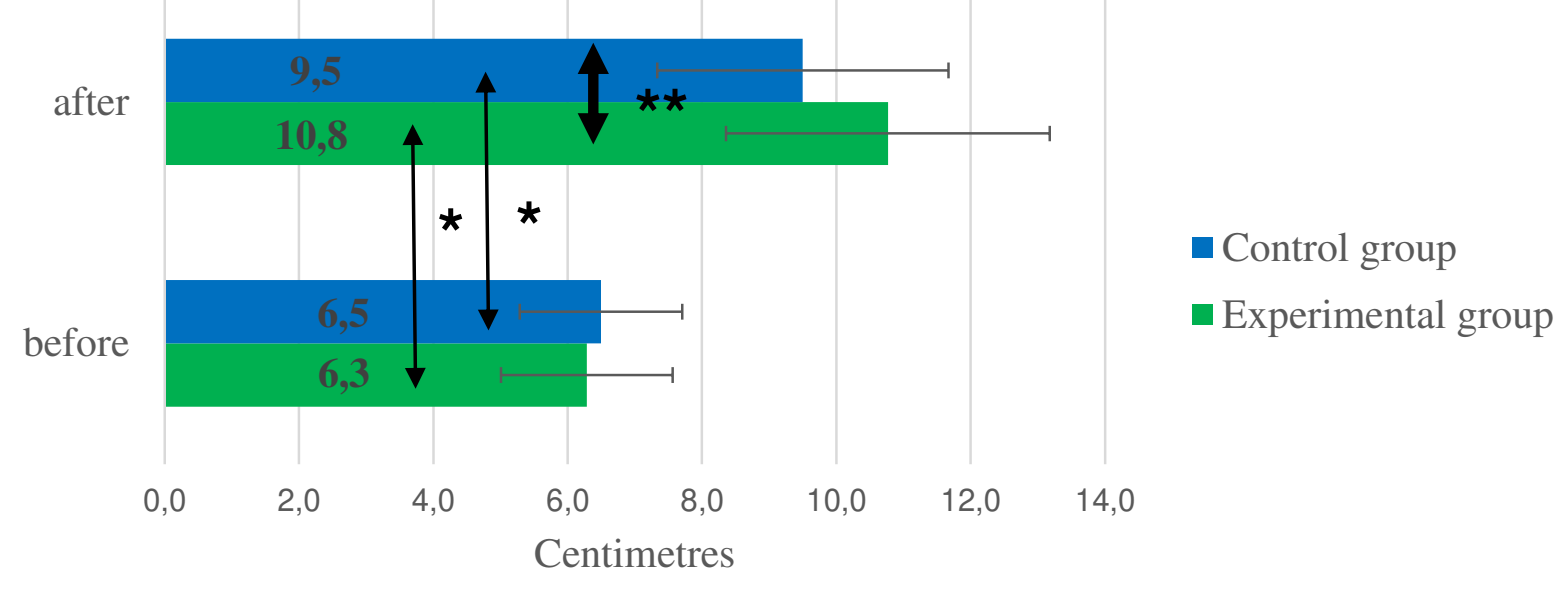

Figure 2. Schober's test results before and after different rehabilitation programs $\left({ }^{*} p<0,05 ;{ }^{* *} p<0,05\right)$.

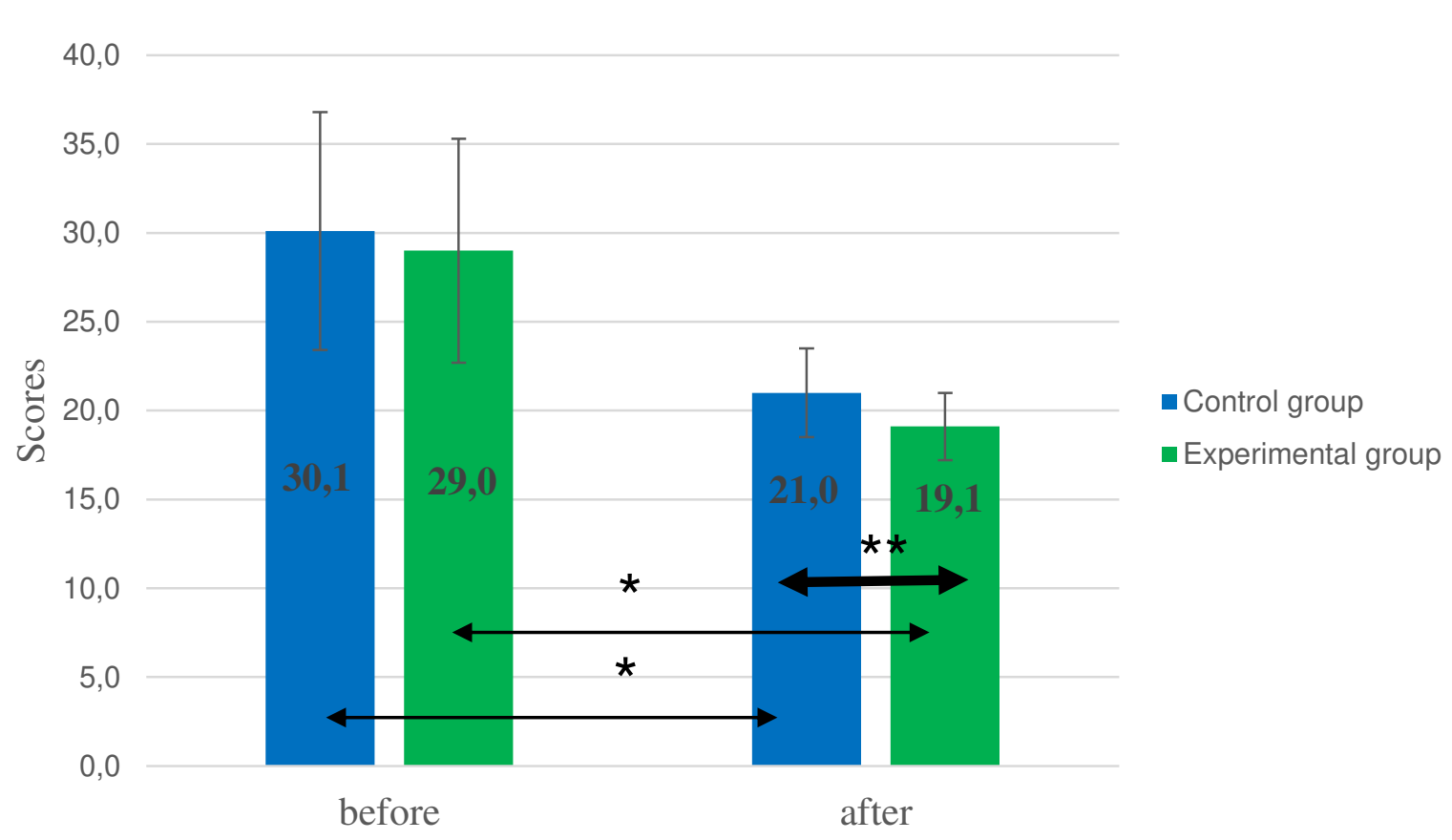

Figure 3. TAMPA Scale for Kinesiophobia results before and after different rehabilitation programs $\left({ }^{*} p<0,05 ;{ }^{* *} p<\right.$ $0,05)$.

Conclusions. 1. Core stability exercises with Dr. Wolff trainers is more suitable for exercising trunk mobility by leaning forwards and returning to a straight position rather than the traditional core stability exercises $(p<0.05)$. The lumbar stabilisation exercises and exercises with Dr. Wolff trainers have equal effect and increase human functional status ( $p>0.05)$. 2. Core stability exercises with Dr. Wolff trainers showed statistically significant results in reducing the fear of movement better than the traditional core stability exercises $(p<0.05)$. 